\title{
Nonuse of bicycle helmets and risk of fatal head injury: a proportional mortality, case-control study
}

\author{
Navindra Persaud MD MSc, Emily Coleman BA, Dorothy Zwolakowski BA, Bert Lauwers MD, Dan Cass MD
}

\begin{abstract}
Background: The effectiveness of helmets at preventing cycling fatalities, a leading cause of death among young adults worldwide, is controversial, and safety regulations for cycling vary by jurisdiction. We sought to determine whether nonuse of helmets is associated with an increased risk of fatal head injury.
\end{abstract}

Methods: We used a case-control design involving 129 fatalities using data from a coroner's review of cycling deaths in Ontario, Canada, between 2006 and 2010. We defined cases as cyclists who died as a result of head injuries; we defined controls as cyclists who died as a result of other injuries. The exposure variable was nonuse of a bicycle helmet.
Results: Not wearing a helmet while cycling was associated with an increased risk of dying as a result of sustaining a head injury (adjusted odds ratio [OR] 3.1, 95\% confidence interval $[\mathrm{Cl}]$ 1.3-7.3). We saw the same relationship when we excluded people younger than 18 years from the analysis (adjusted OR $3.5,95 \% \mathrm{Cl} 1.4-8.5)$ and when we used a more stringent case definition (i.e., only a head injury with no other substantial injuries; adjusted OR 3.6, 95\% Cl 1.2-10.2).

Interpretation: Not wearing a helmet while cycling is associated with an increased risk of sustaining a fatal head injury. Policy changes and educational programs that increase the use of helmets while cycling may prevent deaths.
Competing interests: None declared.

This article has been peer reviewed.

Correspondence to: Navindra Persaud, nav.persaud@utoronto.ca

CMAJ 2012. DOI:10.1503 /cmaj.120988
$\mathrm{O}$ ne cyclist dies in Canada each week, and cycling fatalities account for more than $2 \%$ of traffic fatalities, a leading cause of death in young adults. ${ }^{1}$ Cycling safety regulations vary by jurisdiction, and controversy remains about the effectiveness of safety measures such as helmets. There is strong evidence that helmets prevent nonfatal head injuries, ${ }^{2}$ but very limited evidence exists related to fatal head injuries. A meta-analysis of case-control studies showed a protective effect of helmets against head injuries, but it was based on just 4 case fatalities in which helmets were not worn. ${ }^{3}$ Another large study involving 1710 cycling collisions found a trend toward a protective effect of helmets, but included only 14 fatalities. ${ }^{4}$ The existing literature leaves open the possibility that helmets prevent nonfatal head injuries, but not fatal ones.

We sought to determine whether cycling without a helmet was associated with an increased risk of sustaining a fatal head injury.

\section{Methods}

\section{Study population}

We used a proportional mortality, case-control design using data from a coroner's review of cycling fatalities in Ontario, Canada. The review was conducted by the Office of the Chief Coro- ner for Ontario and involved all accidental cycling deaths occurring in the province between January 2006 and December 2010. ${ }^{5}$ According to Ontario's Coroners Act, all deaths that are sudden and unexpected, or from any cause other than disease, must be reported to a coroner.

We reviewed the reports of the investigating coroner, police incident reports and accident reconstruction reports. We used a standardized computerized form for data abstraction, including the age and sex of the cyclist and driver (or pedestrian, for incidents between cyclists and pedestrians), the mechanism of death, the results of postmortem examination, the cause of death, the clothing worn by the cyclist, helmet use and the use of bicycle safety equipment, such as lights.

\section{Statistical analysis}

We defined cases as fatalities included in the coroner's review for which the cause of death was a head injury (including traumatic head injury, closed head injury, craniocerebral trauma and similar terms); we defined controls as fatalities for which the cause of death was not a head injury. We calculated odds ratios [ORs], correcting for age and sex using logistic regression. Our prespecified test was for an association between risk of death from a fatal head injury and not wearing a helmet. No data were missing. 


\section{Results}

There were 129 accidental cycling deaths between Jan. 1, 2006, and Dec. 31, 2010. Decedents ranged in age from 10 to 83 years, and most of them were boys or men $(86 \%, 111 / 129)$ (Table 1). Most collisions $(77 \%, 99 / 129)$ involved a motor vehicle (Table 2).

\begin{tabular}{|lcc|}
\hline \multicolumn{2}{|c|}{ Table 1: Characteristics of cases and controls } \\
\hline Characteristic & $\begin{array}{c}\text { Cases* } \\
n=71\end{array}$ & $\begin{array}{c}\text { Controls } \\
n=58\end{array}$ \\
\hline Males, no. (\%) & $60(84)$ & $51(88)$ \\
\hline Age, mean \pm SD & $43 \pm 21$ & $41 \pm 19$ \\
\hline Age, yr & & \\
\hline$<18$ & $10(14)$ & $6(10)$ \\
\hline $18-29$ & $12(17)$ & $10(17)$ \\
\hline $30-39$ & $5(7)$ & $7(12)$ \\
\hline $40-49$ & $17(24)$ & $15(26)$ \\
\hline $50-59$ & $9(13)$ & $7(12)$ \\
\hline $60-69$ & $9(13)$ & $10(17)$ \\
\hline$>69$ & $9(13)$ & $3(5)$ \\
\hline $\begin{array}{l}\text { Note: SD = standard deviation. } \\
\text { *Cause of death was a head injury. }\end{array}$ \\
\hline
\end{tabular}

Table 2: Types of incidents leading to injuries of cases and controls

\begin{tabular}{|lcc|}
\hline Type of incident & $\begin{array}{c}\text { Cases, no. (\%)* } \\
n=71\end{array}$ & $\begin{array}{c}\text { Controls, no. (\%) } \\
n=58\end{array}$ \\
\hline Collision with motor vehicle & $55(77)$ & $44(76)$ \\
\hline Collision with other bicycle & $2(3)$ & $0(0)$ \\
\hline Collision with pedestrian & $1(1)$ & $0(0)$ \\
\hline Collision with other object & $5(7)$ & $7(12)$ \\
\hline No collision (fall) & $8(11)$ & $7(12)$ \\
\hline *Cause of death was a head injury. & & \\
\hline
\end{tabular}

Table 3: Odds of death from a head injury when not wearing a helmet while cycling, with and without other substantial injuries

\begin{tabular}{|c|c|c|c|c|}
\hline \multirow[b]{2}{*}{ Case definition } & \multicolumn{2}{|c|}{$\begin{array}{c}\text { Fraction not } \\
\text { wearing a helmet }\end{array}$} & \multirow[b]{2}{*}{ OR $(95 \% \mathrm{Cl})$} & \multirow{2}{*}{$\begin{array}{l}\text { Adjusted* } \\
\text { OR }(95 \% \mathrm{Cl})\end{array}$} \\
\hline & Cases & Controls & & \\
\hline $\begin{array}{l}\text { Head injury as } \\
\text { cause of death } \\
\text { with other } \\
\text { injuries }\end{array}$ & $58 / 71$ & $37 / 58$ & $2.5(1.2-5.7)$ & $3.1 \quad(1.3-7.3)$ \\
\hline $\begin{array}{l}\text { Head injury as } \\
\text { cause of death } \\
\text { with no other } \\
\text { injuries }\end{array}$ & $38 / 43$ & $57 / 86$ & $3.9(1.4-10.9)$ & $3.6(1.2-10.2)$ \\
\hline
\end{tabular}

Death due to a head injury (with or without other substantial injuries) showed a significant association with not wearing a helmet while cycling (Table 3). A similar relationship was seen if only adults (age $18 \mathrm{yr}$ and older) were considered (OR 2.87, 95\% confidence interval [CI] 1.26.4; adjusted OR 3.5, 95\% CI 1.4-8.5). The odds were similar when a more stringent case definition was used: head injury as cause of death with no other substantial injuries.

Using a less conservative control definition of only incidents in which the cyclist was run over (and therefore where death could not have been prevented by wearing a helmet), the control prevalence of not wearing a helmet was $47 \%$ (7/15; OR 7.1, 95\% CI 2.0-28).

\section{Interpretation}

In this case-control study involving 129 cycling deaths, we saw an association between dying as a result of sustaining a head injury and not wearing a helmet. These results are consistent with a protective effect of helmets on cycling deaths.

The OR we calculated for helmet use is similar to those calculated from studies of helmet use in nonfatal collisions that employed methods similar to ours. ${ }^{6-9}$ Thompson and colleagues ${ }^{6}$ reviewed 3390 cyclists presenting to emergency departments in Seattle, Washington, for injuries sustained in crashes. They defined cases as cyclists who sustained brain injuries, whereas controls were defined as cyclists who sustained any other injuries. They found that cases $(29 \%)$ were less likely to have been wearing helmets than controls (56\%) (OR 3.2, 95\% CI 2.7-3.8). These findings and ours are consistent with a meta-analysis that found a risk reduction of $65 \%$ for nonfatal head injuries with the use of helmets. ${ }^{2}$

The enactment of legislation promoting helmet use is associated with an increase in helmet use and a decrease in head injuries. ${ }^{10}$ For example, in Victoria, Australia, helmet use increased from $31 \%$ to $75 \%$, and cycling fatalities decreased by $48 \%$, after the introduction of mandatory helmet laws, despite an increase in cycling among adults. ${ }^{11}$ In Canada, wearing helmets is more common in provinces with mandatory helmet laws. ${ }^{12}$

\section{Limitations}

Our analysis is dependent on helmet use being reported similarly regardless of the cause of death. The similarity between helmet use in the control group (36\%) and that reported in the Canadian Community Health Survey ${ }^{12}(34 \%)$ is 
consistent with the group of cycling fatalities involving injuries other than head injuries being an appropriate control, and suggests that helmet use was not underreported for controls.

The OR we calculated may underestimate the risk of a fatal head injury when a helmet is not worn for several reasons. The control group may have included some cyclists who died because they were not wearing a helmet (i.e., cyclists who may have survived their other injuries if they had not also sustained a head injury), which would increase the prevalence of not wearing a helmet among control fatalities. Furthermore, helmets may not have been worn properly or been in working order at the time of the collision; we were unable to determine the type or status of the helmets worn. In addition, the OR we calculated would underestimate the risk of not wearing a helmet if cyclists who do not wear helmets are more likely to be involved in fatal collisions, because this tendency would increase the number of cyclists not wearing a helmet in both the case and control groups, thereby lessening the difference between groups.

Classification bias in determining cause of death is unlikely, because the cause of death was determined by coroners using a complete list of injuries before the start of our study. The lack of bias is supported by the same association as the primary analysis being found when the more stringent case definition (i.e., the only injury was a head injury) was used.

\section{Conclusion}

Policies and campaigns that promote helmet use may decrease cycling mortality, which contributes substantially to mortality among young adults worldwide. Concomitant educational programs and public awareness campaigns may account for some of the positive effects of enacting helmet legislation. Cyclists less than 18 years of age are required by law to wear a helmet in Ontario. That $88 \%$ of decedents in our study were older than 18 years (and $18 \%$ were $>60 \mathrm{yr}$ ) suggests a gap in public policy.

\section{References}

1. Ramage-Morin PL. Motor vehicle accident deaths, 1979-2004. Health Rep 2008;19:45-51.

2. Thompson DC, Rivara FP, Thompson R. Helmets for preventing head and facial injuries in cyclists. Cochrane Database Systematic Rev 2000;(2):CD001855.

3. Attewell RG, Glase K, McFadden M. Bicycle helmet efficacy: a meta-analysis. Accid Anal Prev 2001;33:345-52.

4. McDermott FT, Lane JC, Brazenor GA, et al. The effectiveness of bicyclist helmets: a study of 1710 casualties. J Trauma 1993; 34:834-44.

5. Office of the Chief Coroner for Ontario. Cycling death review, June 2012. Available: www.mcscs.jus.gov.on.ca/stellent/groups /public/@mcscs/@www/@com/documents/webasset/ec159773 .pdf (accessed 2012 Oct. 2).

6. Thompson DC, Rivara FP, Thompson RS. Effectiveness of bicycle safety helmets in preventing head injuries. A case-control study. JAMA 1996;276:1968-73.

7. Thomas S, Acton C, Nixon J, et al. Effectiveness of bicycle helmets in preventing head injury in children: case-control study. BMJ 1994;308:173-6.

8. Thompson RS, Rivara FP, Thompson DC. A case-control study of the effectiveness of bicycle safety helmets. $N$ Engl J Med 1989;320:1361-7.

9. McDermott FT, Lane JC, Brazenor GA, et al. The effectiveness of bicyclist helmets: a study of 1710 casualties. J Trauma 1993; 34:844-5.

10. Macpherson A, Spinks A. Bicycle helmet legislation for the uptake of helmet use and prevention of head injuries. Cochrane Database Syst Rev 2008;(3):CD005401 10.

11. Cameron MH, Vulcan AP, Finch CF, et al. Mandatory bicycle helmet use following a decade of voluntary promotion in Victoria, Australia — an evaluation. Accid Anal Prev 1994;26:325-37.

12. Bicycle helmet use, 2009. Ottawa (ON): Statistics Canada; 2009. Available: www.statcan.gc.ca/pub/82-625-x/2010002/article /11274-eng.htm (accessed 2012 Aug. 31).

Affiliations: From the Office of the Chief Coroner for Ontario (Persaud, Coleman, Zwolakowski, Lauwers, Cass), Toronto, Ont.; Keenan Research Centre, (Persaud) Li Ka Shing Knowledge Institute, St. Michael's Hospital; the Department of Family and Community Medicine, St. Michael's Hospital, University of Toronto, Toronto, Ont.; the Department of Family and Community (Lauwers), Medicine of McMaster University, Hamilton, Ont.; and the Division of Emergency Medicine (Cass), the University of Toronto, Toronto, Ont.

Contributors: Bert Lauwers and Dan Cass oversaw the coroner's review; Navindra Persaud conceived of this study; Emily Coleman, Dorothy Zwolakowski and Navindra Persaud analyzed the data; Navindra Persaud wrote the first draft of the manuscript; Emily Coleman, Dorothy Zwolakowski, Bert Lauwers and Dan Cass revised the manuscript critically for important intellectual content. All of the authors approved the final version of the manuscript submitted for publication.

Acknowledgements: The authors thank Dr. David Evans for assistance with data collection and analysis. Navindra Persaud is funded by a Banting Postdoctoral Fellowship from the Canadian Institutes of Health Research and by the Department of Family and Community Medicine at St. Micheal's Hospital, Toronto, Ont. 